Research Article

\title{
Transversus Abdominis Plane (TAP) Block: A Comparative Study between Levobupivacaine versus Levobupivacaine plus Ketamine in Abdominoplasty
}

\author{
Radwa F. Mansour $\mathbb{D}^{1},{ }^{1}$ Mohamed A. Afifi $\mathbb{D}^{2},{ }^{2}$ and Mohamed S. Abdelghany $\mathbb{D}^{1}$ \\ ${ }^{1}$ Lecturer of Anesthesia and Surgical ICU, Faculty of Medicine, Tanta University, Tanta, Egypt \\ ${ }^{2}$ Lecturer of Anesthesia and ICU, Alazhar Faculty of Medicine in Cairo, Alazhar University, Cairo, Egypt \\ Correspondence should be addressed to Radwa F. Mansour; rodywael@yahoo.com
}

Received 19 June 2021; Revised 23 September 2021; Accepted 11 October 2021; Published 31 October 2021

Academic Editor: Giustino Varrassi

Copyright ( $\odot 2021$ Radwa F. Mansour et al. This is an open access article distributed under the Creative Commons Attribution License, which permits unrestricted use, distribution, and reproduction in any medium, provided the original work is properly cited.

Purpose. We conducted this study to explore the hypothesis that the addition of ketamine to levobupivacaine in ultrasound-guided Transversus Abdominis Plane (TAP) block would result in a better and prolonged duration of postoperative analgesia for patients undergoing abdominoplasty. Material and Methods. This randomized prospective study was conducted on 50 patients who were scheduled for abdominoplasty. TAP block was performed bilaterally for all patients either with levobupivacaine $0.5 \% 15 \mathrm{ml}$ plus ketamine $0.5 \mathrm{mg} / \mathrm{kg}$ in a total volume of $20 \mathrm{ml}$ in the LK group $(n=25)$ or with levobupivacaine $0.5 \% 15 \mathrm{ml}$ plus $5 \mathrm{ml}$ normal saline in a total volume of $20 \mathrm{ml}$ in the L group on each side. Results. Visual analogue scale (VAS) was significantly lower in the LK group in resting condition at 6,12 , and $16 \mathrm{~h}$ postoperatively compared to the L group. On movement, the VAS was significantly lower at $4,6,8,12,16$, and $24 \mathrm{~h}$ postoperatively in the LK group compared to the L group. The time for first rescue analgesia was longer in the LK group $(18.7 \pm 4.8 \mathrm{~h})$ than that in the L group $(6.5 \pm 2.4 \mathrm{~h})$ with the reduced total amount of rescue morphine in the LK group $(1.14 \pm 2.2 \mathrm{mg})$ versus the L group $(5.86 \pm 3.6 \mathrm{mg})$. Only six patients in the LK group requested rescue morphine, whereas nineteen patients requested rescue morphine in the L group. Conclusions. In TAP block, adding ketamine $0.5 \mathrm{mg} / \mathrm{kg}$ enhanced the analgesic efficacy of levobupivacaine $0.5 \%$ in patients undergoing abdominoplasty and reduced the required analgesics postoperatively.

\section{Introduction}

One of the most popular aesthetic surgeries is abdominoplasty, which aims to remove excess skin and fat from the abdomen with or without plication of the rectus sheath and liposuction [1,2]. Postoperative pain management has great concern for both the patient and surgeon. Different modalities of analgesia have been employed to decrease pain after abdominoplasty, such as nonsteroidal anti-inflammatory drugs, systemic opioids, epidural analgesia, wound infiltration by local anesthetics, and regional nerve block $[3,4]$.

Transversus Abdominis Plane (TAP) block is a peripheral nerve block that provides analgesia for the anterior abdominal wall from T6-L1 following abdominal surgery. It was described by Rafi in 2001 [5]. The introduction of ultrasound guidance has allowed the technique to be easy to perform and of increased safety and enhanced the quality through direct visualization [6]. TAP block has been administrated as part of multimodal analgesia for patients scheduled for abdominoplasty to decrease postoperative analgesic requirements [7].

Levobupivacaine is a commonly used local anesthetic (LA), but it has a limited duration of analgesia [8]. This has warranted the addition of adjuncts to enhance the quality and duration of analgesia. Ketamine is an N-methyl-D-aspartate (NMDA) receptor antagonist. It has been used as an adjunct to LAs in peripheral nerve blocks and neuraxial anesthesia $[9,10]$.

Therefore, this study aimed to explore the hypothesis that the addition of ketamine to levobupivacaine in ultrasound-guided transversus abdominis plane (TAP) block 
would result in a better and prolonged duration of postoperative analgesia for patients undergoing abdominoplasty.

\section{Material and Methods}

This double-blinded, randomized, and prospective study was conducted at the plastic surgery department after approval of the ethical committee of Faculty of Medicine, Tanta University Hospital (approval number 30915/05/16), followed by registration in the Pan African Clinical Trial Registry (PACTR201703002081320) https://pactr.samrc.ac. $\mathrm{za} /$ TrialDisplay.aspx?TrialID $=2081$. Written informed consent was obtained from 50 patients aged 25-50 years with ASA I and II who were scheduled for abdominoplasty under general anesthesia from March 2017 to August 2019.

Patients with a body mass index "BMI" $>35 \mathrm{~kg} / \mathrm{m}^{2}$, allergy to drugs used, refused participation, coagulation disorders, alcohol or drug abuse, and mental disorder which interferes with visual analogue scale (VAS) evaluation were excluded from the study.

Randomization was performed using the computergenerated list in a closed sealed envelope to randomly allocate the patients into two groups in a $1: 1$ ratio (25 patients in each group) depending on the drug used. TAP block was performed bilaterally for all patients either with levobupivacaine $0.5 \% 15 \mathrm{ml}$ plus ketamine $0.5 \mathrm{mg} / \mathrm{kg}$ in a total volume of $20 \mathrm{ml}$ in the LK group (levobupivacaine + ketamine) or with levobupivacaine $0.5 \% 15 \mathrm{ml}$ plus $5 \mathrm{ml}$ normal saline in a total volume of $20 \mathrm{ml}$ in the $\mathrm{L}$ group (levobupivacaine only) on each side. The study drugs were prepared by an anesthesiologist not involved in the study. The block was performed by another anesthesiologist experienced in the TAP block.

Preoperative assessment and instructions on how to assess the postoperative pain using VAS from $0=$ no pain to $10=$ worst pain were conducted to all patients.

General anesthesia and monitoring, including ECG, pulse oximetry, noninvasive blood pressure, and capnography, were standardized for all patients. On arrival at the operating room $(\mathrm{OR})$, midazolam $(0.02 \mathrm{mg} / \mathrm{kg})$ was given to all patients. Face mask oxygenation for $5 \mathrm{~min}$ was carried out, followed by intubation after induction of anesthesia with propofol $(2 \mathrm{mg} / \mathrm{kg})$, cisatracurium $(0.15 \mathrm{mg} / \mathrm{kg})$, and fentanyl $(1-2 \mu \mathrm{g} / \mathrm{kg})$. Sevoflurane with oxygen air mixture (50:50) was administered for anesthesia maintenance. Controlled mechanical ventilation was adjusting to maintain end-tidal $\mathrm{CO}_{2}$ between $35-40 \mathrm{mmHg}$. All patients received $4 \mathrm{mg}$ of ondansetron. Increments of cisatracurium $(0.01 \mathrm{mg} /$ $\mathrm{kg}$ ) were applied as needed, and fentanyl $(1 \mu \mathrm{g} / \mathrm{kg})$ was given to maintain heart rate and mean arterial blood pressure within $20 \%$ of the baseline. Warmer was applied to avoid intraoperative hypothermia. $10 \mathrm{ml} / \mathrm{kg} / \mathrm{h}$ of Ringer lactate solution was infused throughout the operation.

2.1. The Technique of Ultrasound-Guided TAP Block [6]. After induction of anesthesia, TAP block was performed bilaterally with the guidance of ultrasound (Sonoscape SSI6000 , China) and before surgical incision. An anesthesiologist skilled in TAP block stands on the contralateral side of the block after skin sterilization with povidone-iodine $10 \%$. The high-frequency $(6-12 \mathrm{MHz})$ linear transducer was coated with sterilized disposable drape and placed in the midaxillary line between iliac crest below and costal margin above. Advancement of the needle (22 gauge, $100 \mathrm{~mm}$, Stimuplex A, B. Braun, Germany) using in-plane visualization was performed from medial to lateral. After positioning the needle between the internal oblique muscle and the transversus abdominis muscles, negative aspiration was performed before injecting the local anesthetic to avoid any vascular puncture. Injection of $1 \mathrm{ml}$ of normal saline was performed to identify the correct placement of the needle, followed by injection of the blinded study solution in the form of two boluses, one bolus inferolateral (below the umbilicus), and other bolus superolateral (above the umbilicus). On the contralateral side, the same procedure was employed. Following TAP block, abdominoplasty was performed with the same techniques and by the same surgeon for all patients.

At the end of the procedure, sevoflurane was discontinued and reversal of neuromuscular blockade with $0.02 \mathrm{mg} / \mathrm{kg}$ atropine and neostigmine $0.05 \mathrm{mg} / \mathrm{kg}$ was carried out, followed by tracheal extubation, and then, patients were transferred to the postanesthesia care unit (PACU).

All patients received paracetamol $1 \mathrm{~g}$ intravenously repeated every $6 \mathrm{~h}$ and ketorolac $30 \mathrm{mg}$ intramuscularly repeated every $12 \mathrm{~h}$ as part of the analgesic regimen postoperatively.

Visual analogue score (VAS) was used to evaluate postoperative pain at rest and on movement (knee flexion) at the PACU and then at 2, 4, 6, 8, 12, 16, 20, and $24 \mathrm{~h}$ in the patient ward. Morphine $0.05 \mathrm{mg} / \mathrm{kg}$ was given as rescue of analgesia when VAS was more than or equal to 4 . The number of patients who requested analgesia, time to the first dose of morphine, and the total morphine consumption in the first $24 \mathrm{~h}$ were estimated. Postoperative nausea and vomiting were recorded. Any drug- or technique-related complications (psychomimetic changes as hallucination or agitation and local anesthetic toxicity) were documented. Also, sedation score assessed on a 4point scale (where $0=$ alert, $1=$ quietly awake, $2=$ asleep but easily aroused, and 3 = deep sleep) was recorded. Patients' satisfaction with pain control was evaluated using fivepoint Likert's score at the end of $24 \mathrm{~h}$. The assessment was conducted by an anesthesiologist who was blinded to group allocation.

VAS was our primary outcome. The secondary outcomes were the time for first analgesic requirements, the total morphine consumption during $24 \mathrm{~h}$, the number of patients who requested analgesia, and patients' satisfaction.

2.2. Sample Size. Sample size calculation suggested a minimum of 22 patients in each group based on the results of a previous study [11] to detect a significant difference in VAS at rest of at least $20 \mathrm{~mm}$ at $\alpha$ error of 0.05 , the standard deviation of $23 \mathrm{~mm}$. and power of the study of $80 \%$. We enrolled 25 cases per group to overcome possible dropouts. 
2.3. Statistical Analysis. Data were fed to the computer and analyzed using IBM SPSS software package version 20.0 (Armonk, NY: IBM Corp). The Kolmogorov-Smirnov test was used to verify the normality of variables distribution; comparisons between groups for categorical variables were assessed using the chi-square test (Fisher or Monte Carlo). Student's $t$-test was used to compare two groups for normally distributed quantitative variables. The Mann-Whitney test was used to compare between two groups for not normally distributed quantitative variables. The significance of the obtained results was judged at the $5 \%$ level.

\section{Results}

Fifty patients out of eligible 64 patients were enrolled in this study (Figure 1). The demographic data and the duration of the surgery were comparable between both groups (Table 1).

Visual analogue scale (VAS) was significantly lower in the LK group at resting condition at 6,12 , and $16 \mathrm{~h}$ postoperatively compared to the $\mathrm{L}$ group (Figure 2). On movement, the VAS was significantly lower at $4,6,8,12,16$, and $24 \mathrm{~h}$ postoperatively in the LK group compared to the $\mathrm{L}$ group (Figure 3).

The time for first rescue analgesia was longer in the LK group $(18.7 \pm 4.8 \mathrm{~h})$ than that in the L group $(6.5 \pm 2.4 \mathrm{~h})$. Also, the total amount of rescue morphine was reduced in the LK group $(1.14 \pm 2.2 \mathrm{mg})$ versus the $\mathrm{L}$ group $(5.86 \pm 3.6 \mathrm{mg})$. Only six patients in the LK group requested rescue morphine, whereas nineteen patients requested rescue morphine in the L group (Table 2).

The percentage of patients' satisfaction was higher in the LK group $(P=0.006)$. No significant difference regarding side effects (nausea, vomiting, sedation, and psychomimetic changes) was detected between both groups (Table 3).

\section{Discussion}

Abdominoplasty became one of the most commonly performed aesthetic procedures over the past several years. It is one of the most painful procedures in aesthetic surgery due to the large surgical field, extensive dissection of tissues, plication of abdominal wall muscles, and extensive liposuction. Every step of that procedure provides great pain, so reducing postoperative pain and enhancing recovery is quite challenging. TAP block has been established as a trusted technique for postoperative analgesia after abdominal surgeries that allow early mobilization and recovery; therefore, it can be used as part of a multimodal analgesic approach after abdominoplasty. The performance of the TAP block with the guidance of ultrasound enhanced the quality of the block, allowed accurate positioning of local anesthetics in the correct plane, and decreased the incidence of complications [6].

To our knowledge, the literature review did not reveal any study describing the addition of ketamine to levobupivacaine for TAP block in abdominoplasty. Levpubivacaine is an S-isomer of racemic bupivacaine, which is less cardio, neurotoxic, and equally potent to bupivacaine. Recently, multiple glutamate receptors have been found in peripheral nerve terminals and may contribute to peripheral pain signaling. Injection of NMDA receptor antagonists such as ketamine attenuates pain signals [12].

Ketamine blocks central and peripheral NAMD receptors producing antinociceptive effects. Also, ketamine can enhance analgesia through the inhibition of nitric oxide synthase [13]. Another mechanism that can explain ketamine antinociceptive action is sensitization of the opioid system adding to aminergic (noradrenergic and serotonergic) activation with reuptake inhibition. Additionally, ketamine can produce anti-inflammatory effects that decrease the inflammatory response that occurred early postoperatively [14] and also regulate the mechanisms involved in the chronic pain pathology [15].

The major findings of this study are that adding ketamine to levobupivacaine in the TAP block results in significantly lower VAS in resting conditions at 6,12 , and $16 \mathrm{~h}$ and on movement at $4,6,8,12,16$, and $24 \mathrm{~h}$ postoperatively compared to the levobupivacaine group. Adding ketamine provides prolonged postoperative analgesia up to $18 \mathrm{~h}$ versus $6 \mathrm{~h}$ in the levobupivacaine-only group and decreased the total amount of rescue morphine $(1.14 \pm 2.2$ versus $5.86 \pm 3.6 \mathrm{mg})$. The number of patients who requested analgesia were higher in the L group (76\%) in comparison with the LK group (24\%).

Similar to our study, Locatelli et al. reported that perineural administration of ketamine in combination with levobupivacaine enhanced LA blockade and prolonged the postoperative analgesia during caudal anesthesia for lower abdominal and urological surgery [16].

Another study conducted by Othman et al. [9] showed that adding ketamine $1 \mathrm{mg} / \mathrm{kg}$ in modified pectoral nerve block to bupivacaine $0.25 \%$ in patients who go through modified radical mastectomy prolongs the time to first rescue analgesia with decreased total morphine consumption. Furthermore, El Mourad and Amer [17] evaluated the effects of adding either ketamine $50 \mathrm{mg}$ or dexamethasone $4 \mathrm{mg}$ to bupivacaine $0.5 \%$ for the thoracic paravertebral block in breast cancer surgery. They evidenced the beneficial effects of long duration of postoperative analgesia and reduced the total analgesic consumption.

Many studies have found that the addition of ketamine to LA in central neuraxial blocks and peripheral nerve blockades in a human was a safe and effective way to potentiate the LA effect and reduce the required analgesics in the postoperative period $[12,18,19]$.

In contrast to our results, adding ketamine $30 \mathrm{mg}$ in interscalene brachial plexus block to bupivacaine $0.5 \%$ in a study conducted by Lee et al. [20] showed no enhancement of the onset and the duration of the sensory or the motor blockade. Omar et al. [21] concluded in their study that adding ketamine $(0.5 \mathrm{mg} / \mathrm{kg})$ or tramadol $(1.5 \mathrm{mg} / \mathrm{kg})$ to bupivacaine $0.5 \%$ in paravertebral block dose not enhance the postoperative analgesia.

Ketamine side effects, either cardiovascular or psychomimetic changes, were not observed in any case of the LK group; this could be explained by many ways, e.g., lengthy operation in which the psychomimetic effect of ketamine is masked by the general anesthesia, premedication with 


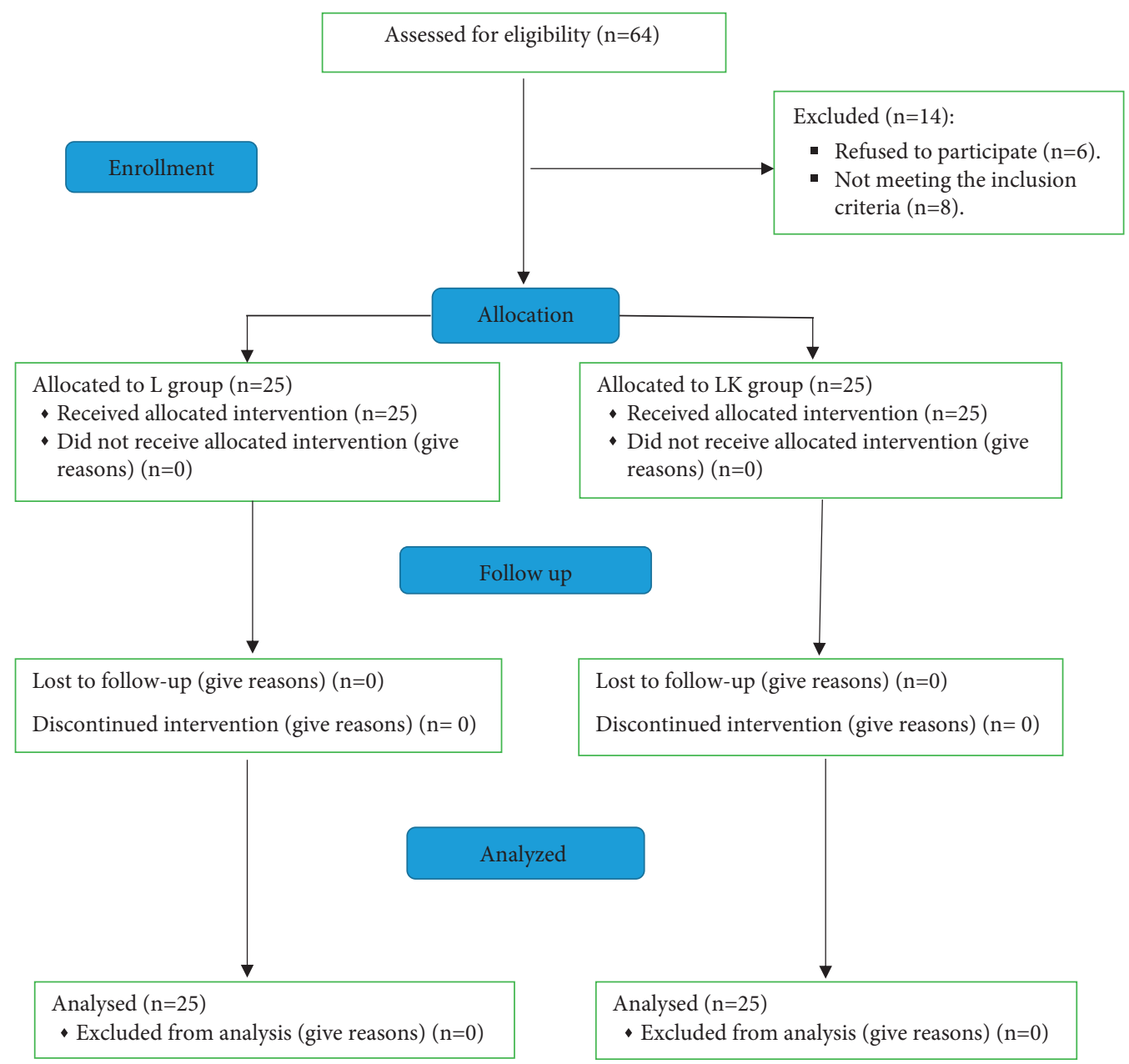

Figure 1: Consort flow chart.

TABle 1: Demographic data and the duration of the surgery

\begin{tabular}{lccc}
\hline & Group L & Group LK & $P$ value \\
\hline Age $(\mathrm{y})$ & $35.2 \pm 7.4$ & $34 \pm 6.1$ & 0.534 \\
Weight $(\mathrm{kg})$ & $76.4 \pm 5.3$ & $74.4 \pm 5.3$ & 0.205 \\
Height $(\mathrm{cm})$ & $160.7 \pm 3.7$ & $160.4 \pm 4.2$ & 0.775 \\
BMI $\left(\mathrm{kg} / \mathrm{m}^{2}\right)$ & $29.6 \pm 2.4$ & $28.9 \pm 1.8$ & 0.267 \\
Sex (female) & $22(12 \%)$ & $23(92 \%)$ & 1.000 \\
$\quad(m a l e)$ & $3(88 \%)$ & $2(8 \%)$ & \\
ASA I/II & $17 / 8$ & $21 / 4$ & 0.596 \\
Duration of the surgery (min) & $183.6 \pm 22.6$ & $190.4 \pm 22$ & 0.284 \\
\hline
\end{tabular}

BMI: body mass index. ASA: American Society of Anesthesiologists. Llevobupivacaine, LK- levobupivacaine + ketamine. Data are expressed as mean \pm SD (standard deviation) or patient number (percentage (\%)). $P<0.05$ is considered significant.

midazolam, the use of a low dose of ketamine $(0.5 \mathrm{mg} / \mathrm{kg})$, and finally, the relatively slower rate of absorption due to low vascularity in TAP.

One of the limitations to the current study is that we did not estimate the serum concentration of ketamine to evaluate whether the action was related to its local effect or due to systemic absorption. Another limitation is that the TAP block was performed after induction of general anesthesia,

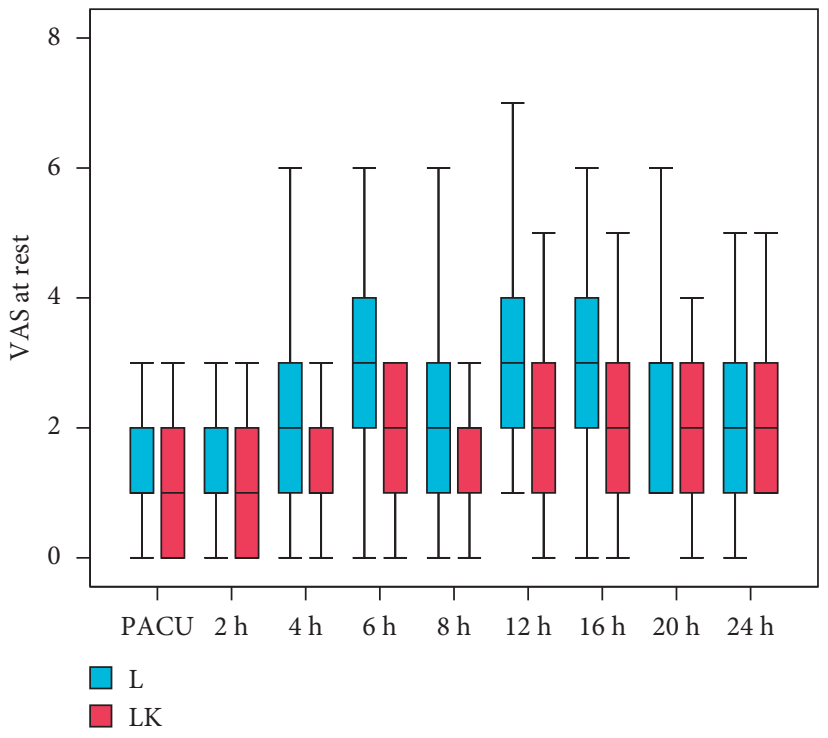

FIgURE 2: Visual analogue scale (VAS) at rest.

so we could not evaluate the success rate of the block. Further studies are needed with different doses of ketamine to determine the ideal one. 


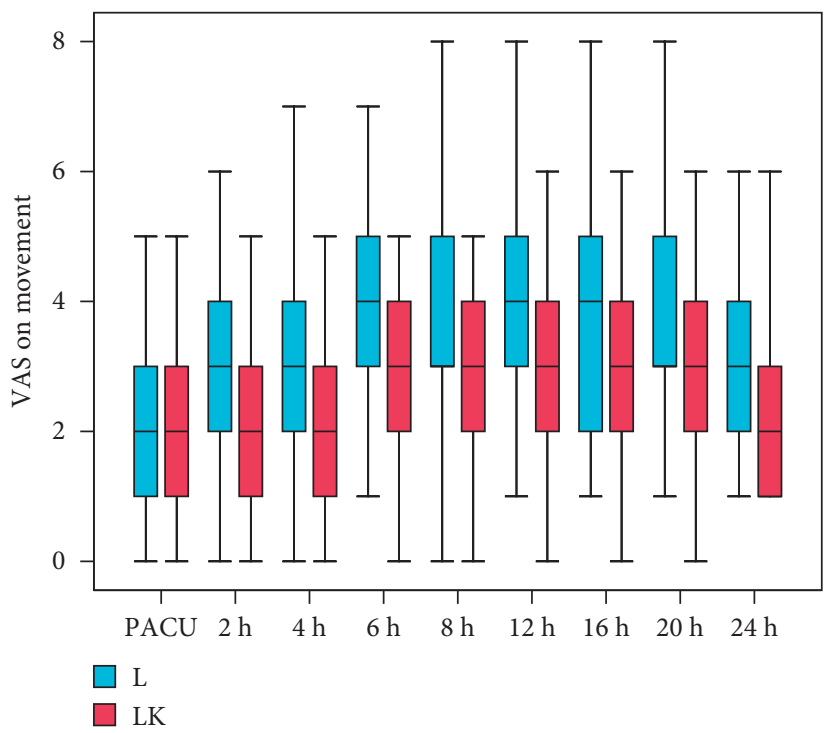

Figure 3: Visual analogue scale (VAS) on movement.

TABle 2: Time to the rescue analgesia, the total analgesic consumption, and the number of patients who requested rescue analgesia.

\begin{tabular}{|c|c|c|c|}
\hline & Group L & Group LK & $P$ value \\
\hline Time to the first rescue analgesia $(\mathrm{h})$ & $\begin{array}{l}6.5 \pm 2.4 \\
6(4-12)\end{array}$ & $\begin{array}{c}18.7 \pm 4.8 \\
18(12-24)\end{array}$ & $<0.001^{*}$ \\
\hline $\begin{array}{l}\text { Total analgesic consumption (mg) } \\
\text { Number of patients who requested rescue analgesia (\%) }\end{array}$ & $\begin{array}{l}5.86 \pm 3.6 \\
19(76 \%)\end{array}$ & $\begin{array}{c}1.14 \pm 2.2 \\
6(24 \%)\end{array}$ & $\begin{array}{c}<0.001^{*} \\
0.001^{*}\end{array}$ \\
\hline
\end{tabular}

L- levobupivacaine, LK- levobupivacaine + ketamine. Data are expressed as mean \pm SD (standard deviation), median (range), or patient number (percentage (\%)). $P<0.05$ is considered significant.

TABLE 3: Patients' satisfaction and side effects.

\begin{tabular}{lcccc}
\hline & & Group & Group & $P$ \\
& & L & LK & value \\
\hline \multirow{3}{*}{ Patient } & 1 & $0(0 \%)$ & $0(0 \%)$ & \\
satisfaction & 2 & $3(12 \%)$ & $0(0 \%)$ & \\
& 3 & $9(36 \%)$ & $2(8 \%)$ & $0.006^{*}$ \\
& 4 & $7(28 \%)$ & $7(28 \%)$ & \\
Side effects & 5 & $6(24 \%)$ & $16(64 \%)$ & \\
& PONV & $3(12 \%)$ & $4(16 \%)$ & 1.000 \\
& Sedation & 0 & 0 & - \\
\hline & Psychomimetic & 0 & 0 & - \\
\hline
\end{tabular}

L- levobupivacaine, LK- levobupivacaine + ketamine. PONV: postoperative nausea and vomiting. Data are expressed as patient number (percentage (\%)). $P<0.05$ is considered significant.

\section{Conclusions}

In TAP block, adding ketamine $0.5 \mathrm{mg} / \mathrm{kg}$ enhanced the analgesic efficacy of levobupivacaine $0.5 \%$ in patients undergoing abdominoplasty and reduced the required analgesics postoperatively.

\section{Data Availability}

Data will be made available on request.

\section{Conflicts of Interest}

The authors declare that there are no conflicts of interest.

\section{References}

[1] T. Fiala, "Tranversus abdominis plane block during abdominoplasty to improve postoperative patient comfort," Aesthetic Surgery Journal, vol. 35, no. 1, pp. 72-80, 2015.

[2] M. A. Abo-Zeid, A.-R. K. Al-Refaey, and A. M. Zeina, "Surgically-assisted abdominal wall blocks for analgesia after abdominoplasty: a prospective randomized trial," Saudi Journal of Anaesthesia, vol. 12, no. 4, p. 593, 2018.

[3] D. D. Kakagia, S. Fotiadis, G. Tripsiannis, and D. Tsoutsos, "Postoperative analgesic effect of locally infiltrated levobupivacaine in fleur-de-lys abdominoplasty," Aesthetic Plastic Surgery, vol. 31, no. 2, pp. 128-132, 2007.

[4] K. A. Hurvitz, W. A. Olaya, A. Nguyen, and J. H. Wells, "Evidence-based medicine: abdominoplasty," Plastic and Reconstructive Surgery, vol. 133, no. 5, pp. 1214-1221, 2014.

[5] A. N. Rafi, "Abdominal field block: a new approach via the lumbar triangle," Anaesthesia, vol. 56, no. 10, pp. 1024-1026, 2001.

[6] P. Hebbard, Y. Fujiwara, Y. Shibata, and C. Royse, "Ultrasound-guided transversus abdominis plane (TAP) block," Anaesthesia \& Intensive Care, vol. 35, no. 4, pp. 616-617, 2007.

[7] A. Araco, J. Pooney, F. Araco, and G. Gravante, "Transversus abdominis plane block reduces the analgesic requirements 
after abdominoplasty with flank liposuction," Annals of Plastic Surgery, vol. 65, no. 4, pp. 385-388, 2010.

[8] R. Acharya, R. Baksi, and P. Mohapatra, "Comparative analysis of duration of postoperative analgesia between levobupivacaine and levobupivacaine with clonidine after ultrasound-guided transversus abdominis plane block in patients undergoing lower segment cesarean section," Anesthesia: Essays and Researches, vol. 12, no. 4, pp. 943-948, 2018.

[9] A. H. Othman, A. El-Rahman, and F. El Sherif, "Efficacy and safety of ketamine added to local anesthetic in modified pectoral block for management of postoperative pain in patients undergoing modified radical mastectomy," Pain Physician, vol. 19, no. 7, pp. 485-494, 2016.

[10] T. Togal, S. Demirbilek, A. Koroglu, E. Yapici, and O. Ersoy, "Effects of S (+) ketamine added to Bupivacaine for spinal anaesthesia for prostate surgery in elderly patients," European Journal of Anaesthesiology, vol. 21, no. 3, pp. 193-197, 2004.

[11] T. Ishida, A. Sakamoto, H. Tanaka et al., "Transversus abdominis plane block with $0.25 \%$ levobupivacaine: a prospective, randomized, double-blinded clinical study," Journal of Anesthesia, vol. 29, no. 4, pp. 557-561, 2015.

[12] M. Tverskoy, M. Oren, M. Vaskovich, I. Dashkovsky, and I. Kissin, "Ketamine enhances local anesthetic and analgesic effects of bupivacaine by peripheral mechanism: a study in postoperative patients," Neuroscience Letters, vol. 215, no. 1, pp. 5-8, 1996.

[13] N. Elia and M. R. Tramèr, "Ketamine and postoperative pain-a quantitative systematic review of randomised trials," Pain, vol. 113, no. 1-2, pp. 61-70, 2005.

[14] J. Sleigh, M. Harvey, L. Voss, and B. Denny, "Ketamine-more mechanisms of action than just NMDA blockade," Trends Anaesth Crit Care, vol. 4, no. 2-3, pp. 76-81, 2014.

[15] L. C. J. Oudejans, M. van Velzen, and A. Dahan, "Ketamine analgesia," Neuropathology of Drug Addictions and Substance Misuse, Elsevier, Tharamani, Chennai, pp. 541-550, 2016.

[16] B. G. Locatelli, G. Frawley, A. Spotti et al., "Analgesic effectiveness of caudal levobupivacaine and ketamine," British Journal of Anaesthesia, vol. 100, no. 5, pp. 701-706, 2008.

[17] M. El Mourad and A. Amer, "Effects of adding dexamethasone or ketamine to Bupivacaine for the ultrasound-guided thoracic paravertebral block in patients undergoing modified radical mastectomy: a prospective randomized controlled study," Indian Journal of Anaesthesia, vol. 62, no. 4, pp. 285-291, 2018.

[18] B. Cook, D. J. Grubb, L. A. Aldridge, and E. Doyle, "Comparison of the effects of adrenaline, clonidine, and ketamine on the duration of caudal analgesia produced by bupivacaine in children," British Journal of Anaesthesia, vol. 75, no. 6, pp. 698-701, 1995.

[19] R. A. Sunder, G. Toshniwal, and G. P. Dureja, "Ketamine as an adjuvant in sympathetic blocks for management of central sensitization following peripheral nerve injury," Journal of Brachial Plexus and Peripheral Nerve Injury, vol. 3, no. 1, pp. 22-26, 2008.

[20] I.-O. Lee, W.-K. Kim, M.-H. Kong et al., "No enhancement of sensory and motor blockade by ketamine added to ropivacaine interscalene brachial plexus blockade," Acta Anaesthesiologica Scandinavica, vol. 46, no. 7, pp. 821-826, 2002.

[21] A. M. Omar, M. A. Mansour, H. H. Abdelwahab, and O. H. Aboushanab, "Role of ketamine and tramadol as adjuncts to bupivacaine $0.5 \%$ in paravertebral block for breast surgery: a randomized double-blind study," Egyptian Journal of Anaesthesia, vol. 27, no. 2, pp. 101-105, 2011. 